\title{
Anemia in Type 2 Diabetes Mellitus (T2dm) and its association with vitamin B12 deficiency
}

\author{
Smriti Rathore ${ }^{1, *}$, Prashant Kumar Singh², Anjana Kumar ${ }^{3}$ \\ ${ }^{1}$ Junior Consultant, ${ }^{3}$ Senior Consultant, Dept, of Pathology, Valencia Hospital, Faridabad, Haryana, ${ }^{2}$ Registrar, \\ Dept. of Medicine, Indraprastha Apollo Hospital, Sarita Vihar, New Delhi, India
}

*Corresponding Author:

Email: dr.smritirathore@yahoo.in

\begin{abstract}
Introduction: India is the diabetic capital of the world. Vitamin B12 deficiency has been recognized since many years ago as an important side effect in diabetic patients who take metformin for more than 5-10 years. This research aimed to determine the prevalence of anemia in type 2 diabetes mellitus (T2DM) and its association with vitamin B12 deficiency due to use of Metformin.

Materials and Methods: Total 200 type 2 diabetes mellitus (T2DM) males and females were included in the study.Blood collection for Fasting blood glucose and Hbalc levels were measured from all participants in tubes without anticoagulant. Hemoglobin, mean corpuscular volume (MCV) were measured by automated cell counters. Measurement of vitamin B12 level was done only in those patients who presented with Macrocytic anemia.

Results: Among 200 patients, 113 patients were on vegetarian. The prevalence of anemia in this study population was 65(32.5\%). 11(16.9\%) were diagnosed as Normocytic Normochromic anemia, 22 (33.8\%) with Microcytic Hypochromic Anemia, 26(40\%) with Macrocytic Anemia and 6(9.2\%) with Dimorphic anemia. Among these 32 patients, who presented with macrocytic and dimorphic anemia, vitamin B12 levels were measured. For 23 vitamin B 12 level was $<200 \mathrm{pg} / \mathrm{ml}$, and for the rest 9 patient's vitamin B12 level was $>200 \mathrm{pg} / \mathrm{ml}$. 149 patients were on Metformin.

Conclusion: Our findings suggest that correction of anemia may have a significant role in prevention of other diabetic complications, thus we recommend that treatment criteria for diabetes should include routine hematological tests and annual screening of Vitamin B12 deficiency along with supplementation should be adopted while treating T2DM.
\end{abstract}

Keywords: Macrocytic Anemia, Type-2 Diabetes Mellitus.

Received: $15^{\text {th }}$ June, 2017

\section{Introduction}

The prevalence of diabetes is swiftly increasing globally at an alarming rate. ${ }^{1}$ India is the diabetic capital of the world. By 2030, about 80 to 87 million people of India will be diabetic and 438 million people $(7.8 \%)$ of the adult population is expected to have diabetes worldwide. ${ }^{2}$ Although diabetes is sometimes considered the major concern for developed nations, the loss of life from premature death among persons with diabetes is greatest in developing countries. India leads the world and stands at the second position after china with 69 million people affected by diabetes. ${ }^{1}$

The Third National Health and Nutrition Examination Survey (NHANES-III) reported that patients with diabetes were twice as likely to have anemia compared to those with similar degree of renal impairment from other causes. ${ }^{3}$ Anemia caused by iron deficiency is more regular in patients with diabetes than without diabetes, and the issue is amplified in patients with renal function impairment. ${ }^{4}$ Vitamin B12 deficiency has been recognized since many years ago as an important side effect in diabetic patients who take metformin for more than 5-10 years. ${ }^{5}$ Diabetic patients with vitamin B12 and/or iron deficiency might be exposed at an expanded danger of unfavorable outcome from diabetic retinopathy, nephropathy, neuropathy, and cardiovascular disease. The etiology of red blood cells frailty in diabetes patients is multifactorial and incorporates aggravation, different insufficiencies, accompanying immune system illnesses, drugs, and hormonal changes notwithstanding renal dysfunction. ${ }^{4}$

Vitamin B12 or cobalamin is a water soluble vitamin that plays a very fundamental role in DNA synthesis, optimal haemopoesis and neurological function. ${ }^{6}$ It is a common cause of macrocytic (megaloblastic) anemia and, in advanced cases, pancytopenia. Neurologic sequelae from vitamin B12 deficiency include paresthesia, peripheral neuropathy, and demyelination of the corticospinal tract and dorsal columns (subacute combined systems disease). ${ }^{7}$ 
Nevertheless, there is an increasing number of diabetic patients without renal impairment who are anemic.To date, there is limited data to determine the occurrence of anemia in diabetics. ${ }^{8}$ Thus, this research aimed to determine the prevalence of anemia in type 2 diabetes mellitus (T2DM) and its association with vitamin B12 deficiency due to use of Metformin.

\section{Materials and Methods}

The study groups were composed of individuals consecutively attended to Valencia Hospital, Faridabad. Hospital Study duration was 12 months (May 2016 to May 2017).

Inclusion criteria: All Type 2 diabetes mellitus males and Females.

Exclusion Criteria: Type I Diabetes mellitus, Cases with hematological disease, pregnant females, and smokers.

Thus, all eligible participants, who were in accordance with the study protocol and who agreed to participate in the study, provided a written informed consent.

WHO guidelines recommend an investigation of anemia when the Hemoglobin $(\mathrm{Hb})$ concentration is $<12 \mathrm{~g} / \mathrm{dl}$ in women and $<13 \mathrm{~g} / \mathrm{dl}$ in men. If we addmean corpuscular volume (MCV) greater than $100 \mathrm{fL}$, we can address the discussion on macrocytic anemia. Anemia was graded as mild, moderate and severe based on the WHO guidelines [Table 1]. ${ }^{9}$

Table 1: WHO criteria for diagnosing anemia and grading

\begin{tabular}{|c|l|c|}
\hline S. N. & Grading & $\begin{array}{c}\text { Haemoglobin } \\
\text { Concentration }\end{array}$ \\
\hline 1. & Mild & $11-12.9 \mathrm{~g} / \mathrm{dl}$ \\
\hline 2. & Moderate & $8-10.9 \mathrm{~g} / \mathrm{dl}$ \\
\hline 3. & Severe & $<8 \mathrm{~g} / \mathrm{dl}$ \\
\hline
\end{tabular}

We examined the patients along with detailed clinical history. $5 \mathrm{ml}$ of blood was drawn from the patient in tubes containing EDTA and it was analyzed in the automated cell counter to measure MCV and Hemoglobin along with peripheral smear examination. Leishman staining was done in the peripheral smears. These deficiencies are readily diagnosed on peripheral blood smear, which shows oval macrocytes, hypersegmented granulocytes, and anisopoikilocytosis. In severe anemia, red blood cell inclusions may include Howell-Jolly bodies, Cabot rings, and punctate basophilia.

Blood collection for Fasting blood glucose and Hbalc levels were measured from all participants. Blood samples were collected in tubes without anticoagulant.Measurement of vitamin B12 level was done only in those patients who presented with Macrocytic anemia.The diagnosis of vitamin B12 deficiency has traditionally been based on low serum vitamin B12 levels, usually less than 200pg per $\mathrm{mL}(150 \mathrm{pmol} / \mathrm{L})$,along with clinical evidence ofdisease. $^{\text {? }}$

\section{Observation and Results}

Table 2: Demographics and clinical characteristics of study population

\begin{tabular}{|l|l|}
\hline \multicolumn{1}{|c|}{ Variables } & \multicolumn{1}{c|}{$\mathbf{N}(\%)$} \\
\hline Gender & $\begin{array}{l}\text { M126 (63\%), F74 } \\
(37 \%)\end{array}$ \\
\hline Age & $<50=58(25 \%)$, \\
& $51-60=65(32.5 \%)$, \\
& $>60=77(38.5 \%)$ \\
\hline Duration of T2DM & $<5 \mathrm{YRS}=79(39.5 \%)$, \\
& $>5 \mathrm{YRS}=121(60.5 \%)$ \\
\hline HbA1c & $<5.6=8(4 \%)$ \\
& $5.7-6.4=26(13 \%)$ \\
& $>6.5=166(83 \%)$ \\
\hline Dietary Habits & Vegetarian= \\
& $113(56.5 \%)$ \\
& Mixed=87(43.5\%) \\
\hline Patients on & 126 \\
Metformin & \\
\hline Anemia & Present=65(32.5\%) \\
& Absent=135(67.5\%) \\
\hline Vitamin B 12 & $<200 \mathrm{pg} / \mathrm{ml}=23$, \\
& $\geq 200 \mathrm{pg} / \mathrm{ml}=9$ \\
\hline
\end{tabular}

Table 3: Classification of anemia based on clinical grading

\begin{tabular}{|l|c|}
\hline \multicolumn{1}{|c|}{ Grading } & N= 65 \\
\hline $\begin{array}{l}\text { Mild (female: } 11-11.9 \mathrm{~g} / \mathrm{dL} ; \\
\text { male: } 11-12.9 \mathrm{~g} / \mathrm{dL})\end{array}$ & $38(58.4 \%)$ \\
\hline Moderate $(8-10.9 \mathrm{~g} / \mathrm{dL})$ & $20(30.7 \%)$ \\
\hline Severe $(<8 \mathrm{~g} / \mathrm{dL})$ & $7(10.7 \%)$ \\
\hline
\end{tabular}

Table 4: Classification of anemia based on morphology

\begin{tabular}{|l|c|}
\hline \multicolumn{1}{|c|}{ Features, Morphology } & N=65 \\
\hline $\begin{array}{l}\text { Normocytic Normochromic } \\
\text { (MCV 80-95 fL, MCH } \geq 27 \mathrm{pg})\end{array}$ & $11(16.9 \%)$ \\
\hline $\begin{array}{l}\text { Microcytic Hypochromic (MCV } \\
<80 \mathrm{fL}, \mathrm{MCH}<27 \mathrm{pg} \text { ) }\end{array}$ & $22(33.8 \%)$ \\
\hline $\begin{array}{l}\text { Macrocytic Normochromic } \\
\text { (MCV > 100 fL) }\end{array}$ & $26(40 \%)$ \\
\hline $\begin{array}{l}\text { Dimorphic (Both Macrocytic and } \\
\text { Microcytic) }\end{array}$ & $06(9.2 \%)$ \\
\hline
\end{tabular}

A total of 200 T2DM patients' data were obtained for this study. Table 2 shows the distribution of demographic and clinical characteristics of the patients. There were 
$126(63 \%)$ male patients. 58 patients were $<50$ years old, 65 were between 50- 60 years of age group. 77 patients were from the age group of $>60$ years old. Mean age was 56.8 years. Patients who had T2DM for $\geq 5$ years were $121(60.5 \%)$. For 8 Patients $\mathrm{HbA} 1 \mathrm{c}$ was <5.6, 26 patients with 5.7-6.4 HbA1c, for rest of the patients $\mathrm{HbA} 1 \mathrm{c}$ was >6.5.Among these 200 already diagnosed diabetic patients, 149 patients were on Metformin. 113 patients were on vegetarian diet.

The prevalence of anemia in this study population was $65(32.5 \%$ ) (Table 3), out of which $38(58.4 \%)$ patients were anemic with hemoglobin <11 g/dl., 20(30.7\%)patients presented with moderate $(8-10.9 \mathrm{~g} / \mathrm{dl})$ and $7(10.7 \%)$ with severe $(<8 \mathrm{~g} / \mathrm{dl})$ anemia.Patients were classified and graded as per WHO criteria. ${ }^{9}$ Anemia was also studied in detail and typed based on the morphology seen in the peripheral smear.

We found that among these 65 diabetic patients, $11(16.9 \%)$ were diagnosed as Normocytic Normochromic anemia, 22(33.8\%) were presented with Microcytic Hypochromic Anemia, 26(40\%) with Macrocytic Anemia and 6(9.2\%) with Dimorphic anemia. (Table 4). Under the term Dimorphic anemia, we have included those anemias whose morphology were having both microcytic and macrocytic features. Among these 32 patients, who presented with macrocytic and dimorphic anemia, vitamin B12 levels were measured. For 23 vitamin B 12 level was $<200 \mathrm{pg} / \mathrm{ml}$, and for the rest 9patient's vitamin B12 level was $>200 \mathrm{pg} / \mathrm{ml}$.

\section{Discussion}

Our study is very much comparable to the study done by Thomas MC, ${ }^{10}$ Adejomo $\mathrm{BI}^{11}$ and Thambiah SC. ${ }^{8}$ In our study, the population consists of mainly aged below 60, which was comparable to other studies along with gender percentage.

The prevalence of anemia in T2DM in our study was high (32.5\%) compared to other studies. Reason may be because, in our study most of these patients were diagnosed with T2DM more than 5 years ago $(60.5 \%)$ and the glucose control was generally poor with a mean FBS of $7.6 \mathrm{mmol} / \mathrm{L}$ and HbA1c of 8.05. Poorly controlled DM can lead to impaired erythropoietin production and release as a result of diabetic autonomic neuropathy. Erythropoietin production and release is regulated in part by autonomic nervous system, suggesting that erythropoietin production could be prematurely impaired in patients with poor glycemic control with diabetic autonomic neuropathy. ${ }^{11}$
The majority of the study population had macrocytic (40\%), while fewer had microcytic $(33.8 \%)$, normocytic (16.9\%) anemia and dimorphic anemia $(9.2 \%)$.

In our study, $49.2 \%$ of the study population had Macrocytic anemia (including dimorphic anemia), which was high as compared to other studies. The most common cause of Macrocytic anemia is Vitamin B12 deficiency. B12 deficiency has been recognized many years ago as an important side effect in diabetic patients who take metformin for more than 5-10 years, ${ }^{4}$ which was used by $149(74.5 \%)$ of the study population.Metformin interferes with vitamin B12 absorption. ${ }^{12}$ Metformin is the most prescribed drug used to treat diabetes (usually, type 2 diabetes) in the world. Its effectiveness is equal to or higher than many others drugs available and has an excellent safety profile for most individuals. ${ }^{4}$ Vitamin B12 malabsorption and its levels may start declining as early as the 4th month after initiating metformin therapy. However due to storage in liver, clinical symptoms of vitamin B12 deficiency may manifest after $5-10$ years. ${ }^{13}$

Metformin hydrochloride is a biguanide which lowers both fasting and post-prandial glucose in type 2 diabetics. It acts mainly by improving insulin sensitivity and decreasing hepatic glucose production. ${ }^{14}$ Metformin treatment appears to reduce blood folate concentrations but not all authors agree. This may be population-dependent. Low folate concentration is also one of the cause of macrocytic anemia. ${ }^{15}$

The principal source of vitamin B12 includes liver, egg yolk, meat, cheese etc. ${ }^{13}$ But in our study most $(56.5 \%)$ of the study population are vegetarian, which can also be the cause of increased number of patients presented with macrocytic anemia.

43\% Patient presented with Microcytic Hypochromic anemia (including dimorphic anemia), which may be because ofiron deficiency, which is prevalent in patients with DM and CKD. Rests of the study population were Normocytic Normochromic. This type of anemia can be seen in cases of poorly controlled T2DM, due to renal involvement.

Thambiah $\mathrm{SC}^{8}$ had done similar study in Malaysia in 165 T2DM patients. $39.4 \%$ patients were anemic, among those $80 \%$ presented with Normocytic Normochromic, because of the renal involvement.

Hematological profile and its significance in T2DM patients were also studied by Thomas $\mathrm{SC},{ }^{10}$ Adejumo BI, ${ }^{11}$ Bharathi K. ${ }^{2}$ In these studies, most of the patients presented with 
Normocytic and Microcytic anemia, which is due to renal involvement and impaired erythropoietinproduction and release as a result of diabetic autonomic neuropathy. Risk of anemia increases significantly with deterioration of renal function. These complications of Diabetes are due to long standing and poorly controlled DM.

\section{Conclusion}

Anemiaisacommon accompaniment to diabetes.It can be because of poor controlled diabetes leading to renal impairment or due to Metformin use leading to Vitamin B12 malabsorption.

As such, regular, early monitoring of $\mathrm{Hb}$ level of T2DM should begin at the primary care setting. So Annual screening of Vitamin B12 deficiency along with supplementation should be adopted while treating T2DM. Correction of anemia may have a significant role in prevention of other diabetic complications, thus we recommend that treatment criteria for diabetes should include routine hematological tests.

\section{References}

1. Akhtar SN, Dhillon P. Prevalence of diagnosed diabetes and associated risk factors: Evidence from the large-scale surveys in India. J Soc Health Diabetes 2017;5:28-36.

2. Bharathi K. Study of hematological profile and its signicance in type 2 diabetes mellitus patients. Journal of Diagnostic Pathology and Oncology, 2016;1(1):14-7.

3. Astor BC, Muntner P, Levin A, et al. Association of kidney function with anemia - The Third National Health and Nutrition Examination Survey (1988-1994). Arch Intern Med 2002;162(12):1401-8.

4. Onel AF, Cotorâcil CA, Răducan D, Trofenciuc NM, Onel C, Popa AR. Metformin and macrocytic anemia. Medical connections 2016;3(43):35-6.

5. Gholoobi A. A Case of Metformin-Related Megaloblastic Anemia Presenting with Palpitation. Patient SafQualImprov. 2015;3(1):234-7.

6. Kibirige D, Mwebaze R. Vitamin B12 deficiency among patients with diabetes mellitus: is routine screening and supplementation justified? Journal of Diabetes \& Metabolic Disorders 2013;12:17

7. Robert C, David L. Vitamin B12 Deficiency. American Family Physician, 2003;67(5):979-86.

8. Thambiah SC, Samsudin IN, George E, Ranjit LK, Saat NS, Hussein Z, et al. Anaemia in Type 2 Diabetes Mellitus (T2DM) Patients in Hospital Putrajaya. Malaysian Journal of Medicine and Health Sciences 2015;11(1):49-61.

9. World Health Organization: Nutritional Anemia: Report of a WHO Scientific Group. Geneva, World Health Org., 1968
10. Thomas MC, Macisaac RJ, Tsalamandris C, Power D, Jerums G. Unrecognized Anemia in Patients With Diabetes. Diabetes Care 2003;26:1164-9.

11. Adejumo BI, Dimkpa U, Ewenighi CO, Onifade AA, Mokogwu AT, Erhabor TA, et al.Incidence and risk of anemia in type-2 diabetic patients in the absence of renal impairment. Health 2012;4:304-8.

12. Sanket K, Swati C. A Study of the Prevalence of Serum Vitamin B12 and Folic Acid Deficiency in Western Maharashtra. J Family Med Prim Care. 2015 Jan-Mar;4(1):64-8.

13. Jeetendra S, Tushar B. Metformin Use and Vitamin B12 Deficiency in Patients with Type-2 Diabetes Mellitus. MVP Journal of Medical Sciences, 2016;3(1):67-70.

14. Cheong B. Metformin: A Differential Diagnosis for Weight Loss, Altered Bowel Habits and B12 Deficiency Anemia in an Elderly. DiabeticMed J Malaysia, 2013;68(5):441-2.

15. Hillson R.Diabetes and the blood - red cells. Practical Diabetes, 2015;32(4):1-2. 